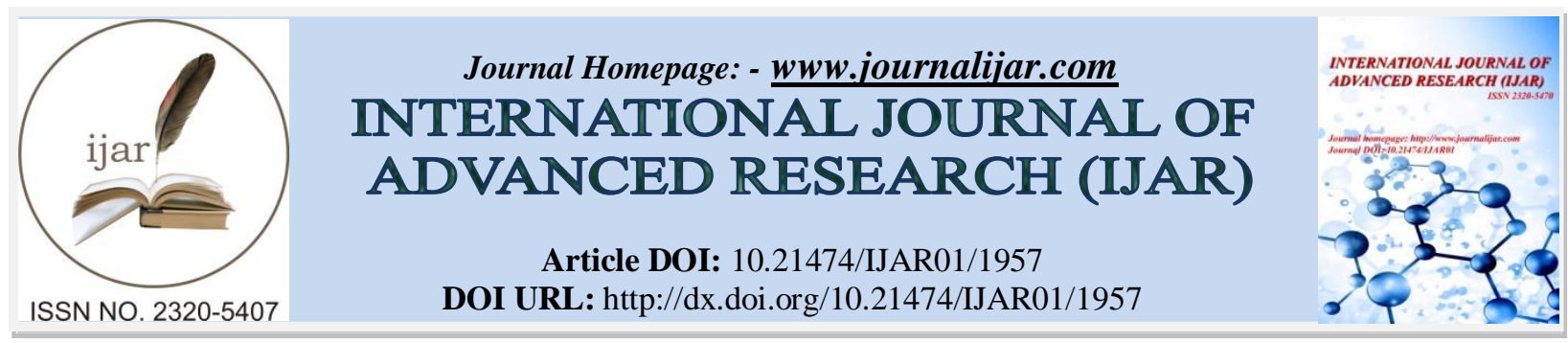

RESEARCH ARTICLE

\title{
REMOVAL OF DYE FROM AQUEOUS SOLUTION BY PINEAPPLE PEEL ACTIVATED CARBON AS AN ADSORBENT.
}

P. D. Ashtaputrey and S. D. Ashtaputrey.

Department of Chemistry, Institute of Science, Nagpur, MS, India, 440001.

\section{Manuscript Info}

Manuscript History

Received: 19 August 2016

Final Accepted: 22 September 2016

Published: October 2016

Key words:-

Activated carbon, Pineapple peel,

Adsorption, Dye removal efficiency

\section{Abstract}

In the present paper we have studied the dye removal efficiency for Congo red and Methylene blue dye from the aqueous solution by the phenomenon of adsorption. The low cost agricultural waste Pineapple Peel acid activated carbon (PPAC) prepared at three different temperatures $300^{\circ} \mathrm{C}, 400^{\circ} \mathrm{C}, 500^{\circ} \mathrm{C}$ were used in the present study. Batch experiments were carried out to determine the effect of various parameters such as different initial concentration of dye, Adsorbent dose and Contact time on the dye removal efficiency of activated carbons from the aqueous solution. The experimental results indicate that percentage dye removal efficiency was the highest for PPAC300 and the lowest in case of PPAC500 with respect to the studied parameters. The PPAC300 activated carbon is more suitable for the removal of synthetic dyes from industrial effluents.

Copy Right, IJAR, 2016,. All rights reserved.

\section{Introduction:-}

Water is the most essential for every living thing including plants, animals and human beings on earth in day to day life. The existence of life without water is impossible hence quality of water is of prime importance. Due to the industrial growth, water is being getting polluted as the water used by industries is directly or indirectly discharged as effluent that contains untreated dyes and other unused excess chemicals into the natural water bodies with or without proper treatment. Dye is a chemical compound utilized for imparting color to the variety of objects. Dye develops its color in water therefore dyes in water do not permit the sunlight to penetrate into the water and hence prevent the process of photosynthesis (Shobin et al., 2005). It also consumes the dissolved oxygen in water which cause ecological imbalance in aquatic life (Yue et al., 2011). Dyes undergo chemical changes under environmental conditions and the transformation products may be more toxic and carcinogenic than the parent dye (Namasivayam et al., 2004). This results in contamination of water resources with many toxic and hazardous chemical impurities. The industries that particularly involved in the manufacturing of textiles, paints, leather tanning, cosmetics, paper, carpets, food, printing etc. make extensive use of dyes for coloring their products and are mainly responsible for the water contamination with dyes. Hence the people residing in the vicinity of industries face many health and environmental problems (Bansal,1996). In recent years, the contamination of water by dyes becomes a great problem in the world as the dyes are highly resistant to light, $\mathrm{pH}$ and microbial attack that makes them to remain in the environment for longer period of time (Wong et al., 2013). Hence removal of these toxic dyes from industrial colored waste water before it get discharged into the water bodies is essential to protect environment and aquatic system. 
There are many physico-chemical methods reported for the removal of dyes from industrial waste water like precipitation, coagulation, sedimentation, flotation, ion exchange, reverse osmosis, solvent extraction and electrolytic process. But all these methods do not show significant effectiveness and economic advantages (Shobin et al., 2005). Hence in addition to these techniques some other method which is significantly effective, economical and eco-friendly is of prime importance for the removal of dyes from aqueous solution. Adsorption has been found to be more superior to the other techniques for water reuse by removing the dye impurity from it. Adsorption by activated carbon derived from agricultural waste is a well known and suitable method for effective removal of toxic dyes from industrial waste water due to its high surface area, low cost and easily availability. Many researchers have already reported the application of activated carbon derived from agricultural waste like rice husk (Jain et al.,2006), saw dust (Nimkar,Chavan.,2014), Clay (Gursec et al.,2004), corn cobs (Mohammad Abd Muslim et al.,2016), tea waste (Uddin et al.,2009), coconut husk (Low et al.,1990), coir pith (Namasivayam et al.,1994), banana pith (Namasivayam et al.,1998), sugarcane Bagasse (Azar et al.,2005) etc. for the removal of toxic dyes from industrial waste water

The application of activated carbon prepared from Pineapple peel by chemical activation process for the removal of toxic dye from aqueous solution has not been reported. Pineapple (Ananas comosus) holds the third rank in the world of tropical fruit production after Banana and Citrus (Nadzirah et al.,2013). It belongs to Bromeliaceae family. The objective of this research is to study the applicability of previously prepared and characterized Pineapple peel activated carbon (Ashtaputrey et al.,2016) towards the toxic dye removal efficiency under different conditions like varying initial concentration of dyes, Adsorbent dose and Contact time by performing batch experiments. The dyes selected for the present work are the Methylene blue (Molecular formula- $\mathrm{C}_{16} \mathrm{H}_{18} \mathrm{~N}_{3} \mathrm{SCl}$, Molecular mass-319.8522 $\mathrm{g} / \mathrm{mol}$ ) and Congo red (Molecular formula- $\mathrm{C}_{32} \mathrm{H}_{22} \mathrm{~N}_{6} \mathrm{Na}_{2} \mathrm{O}_{6} \mathrm{~S}_{2}$, Molecular mass-696.6632 g/mol)

\section{Experimental:-}

\section{Adsorbent:-}

The Pineapple peel activated carbons (PPAC) prepared by the chemical activation using $1 \mathrm{~N} \mathrm{HCl}$ solution at temperatures $300^{\circ} \mathrm{C}, 400^{\circ} \mathrm{C}$ and $500^{\circ} \mathrm{C}$ were used as an adsorbent for the present study. These activated carbons were labelled as PPAC300, PPAC400 and PPAC500 respectively (Ashtaputrey et al., 2016). The basic characteristics of activated carbons (PPAC) like $\mathrm{P}^{\mathrm{H}}$, Conductivity, Moisture content, Ash content, Volatile content, Iodine value, Methylene blue value and Fixed carbon were analyzed by standard procedures of ASTM, BIS and CEFIC. The surface morphology analysis of adsorbents was carried out by Scanning Electron Microscopic (SEM) technique.

The observed various physico-chemical characteristics values of activated carbons PPAC (Ashtaputrey et al., 2016) are reported in table: 1.

Table 1:- Physico-chemical characteristics values of activated carbons PPAC.

\begin{tabular}{|l|l|l|l|l|}
\hline Sr. No. & Characteristics & PPAC300 & PPAC400 & PPAC500 \\
\hline 1 & $\mathrm{P}^{\mathrm{H}}$ & 6.84 & 5.81 & 6.36 \\
\hline 2 & Conductivity $(\mu \mathrm{S})$ & 1022.7 & 978.3 & 1142.5 \\
\hline 3 & Ash Content $(\%)$ & 24.58 & 27.15 & 31.17 \\
\hline 4 & Volatile Content $(\%)$ & 42.27 & 40.21 & 38.23 \\
\hline 5 & Moisture Content $(\%)$ & 18.32 & 15.94 & 13.73 \\
\hline 6 & Iodine Value $(\mathrm{mg} / \mathrm{g})$ & 45.14 & 1040.95 & 967.58 \\
\hline 7 & Methylene blue Value $(\mathrm{mg} / \mathrm{g})$ & 286 & 233 & 158 \\
\hline 8 & Fixed Carbon $(\%)$ & 14.83 & 16.70 & 16.87 \\
\hline
\end{tabular}

\section{Preparation of Adsorbate:-}

The dyes selected for the present work are the Methylene blue and Congo red. The aqueous solution of the dye Congo Red (CR) and Methylene Blue (MB) were prepared by dissolving both dyes in distilled water. $1000 \mathrm{ppm}$ stock solutions of each dye (CR, MB) were prepared. Further the solutions of various concentrations were obtained by diluting the $1000 \mathrm{ppm}$ stock solution with distilled water.

\section{Batch Experiments:-}

All the dyes used in the present work were purchased from the local market and were used further without their purification. All solutions were made in distilled water. Batch adsorption experiments were performed to study the 
dye removal efficiency of PPACs from aqueous solution under various conditions like different initial concentration of dyes (20,40,60, 80, $100 \mathrm{ppm})$, Adsorbent dose (0.2, 0.4, 0.6, 0.8, 1g/100 ml) and Contact time (30, 60, 90, 120, 150 minutes). Optical absorption observations were made keeping the other conditions constant except for the one in which its effect is studied for all PPACs. All the experiments were performed at room temperature in stoppard glass flask. In each experiment a known amount of activated carbon was added to $100 \mathrm{ml}$ of aqueous dye sample solution with known initial concentration at neutral $\mathrm{p}^{\mathrm{H}}$ and vigorously shaken. After which the content of the flask were filtered by using whatmann filter paper. The filtrates were collected after rejecting first few $\mathrm{ml}$ of it. The absorbance of the filtrate was then determined using UV-Visible Spectrophotometer at wavelength $\lambda_{\max }=497 \mathrm{~nm}$ for Congo red (Sharma et al., 2008) and wavelength $\lambda_{\max }=668 \mathrm{~nm}$ for Methylene Blue (Wong et al., 2013).

Analysis of removal efficiency:-

Toxic dye removal efficiency of PPACs from the aqueous sample solution under different conditions was calculated using the following equation. MS excel were used to performed the statistical calculations and plotting graphs.

$\%$ Dye removal efficiency $=\frac{C i-C f}{C i} \times 100$

Where $C i=$ Initial absorbance value before the dyes are treated and

$C f=$ Final absorbance value after the dyes are treated

\section{Results and Discussion:-}

The percentage removal efficiency of PPACs for toxic dyes (CR, MB) under different conditions is discussed below.

\section{Effect of initial dye concentration:-}

This effect was studied by taking 20,40, 60, 80 and 100 ppm initial concentrations of dyes and using $0.5 \mathrm{~g} / 100 \mathrm{ml}$ of adsorbent dose of PPACs at neutral $\mathrm{pH}$ and one hour contact time. It was observed that the percentage removal efficiency of adsorbent is dependent on initial concentration of toxic dyes in aqueous sample solution and it decreases with increase in initial concentration. The results obtained are shown in figure: 1 . It can be seen from the figure that the percentage removal efficiency is maximum for $20 \mathrm{ppm}$ solutions and further decreases to constant value with increase in initial concentration of dye for all adsorbents. It is due to the fact that at low initial dye concentration sufficient adsorption sites are available for adsorption of dyes. However at higher concentrations the numbers of dye molecules are relatively higher as compare to available adsorption sites thus there is saturation of active binding sites on the activated carbon surface at high dye concentration (Ishaq et al., 2014). The percentage removal efficiency is more for Congo red dye than that of the Methylene blue dye for all PPACs. The percentage removal efficiency of PPAC300 is maximum in comparison with others. At 20 ppm initial concentration PPAC300 adsorbent found to remove $73.27 \%$ Congo red and $68.61 \%$ Methylene blue dye.

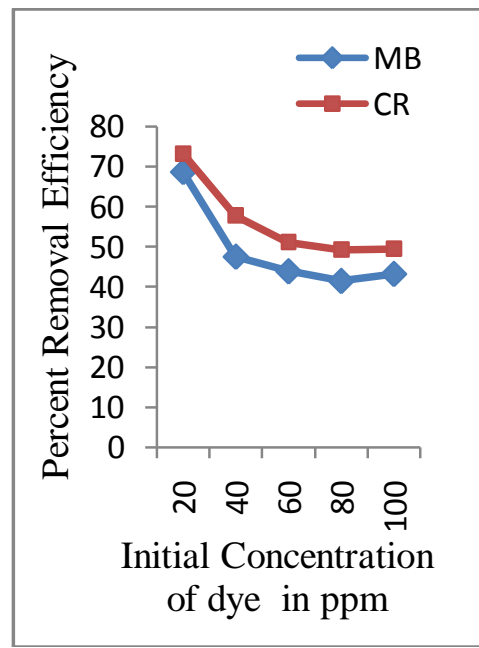

a

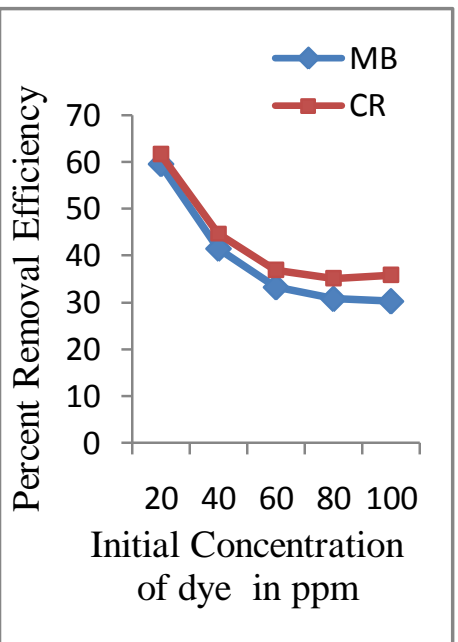

b

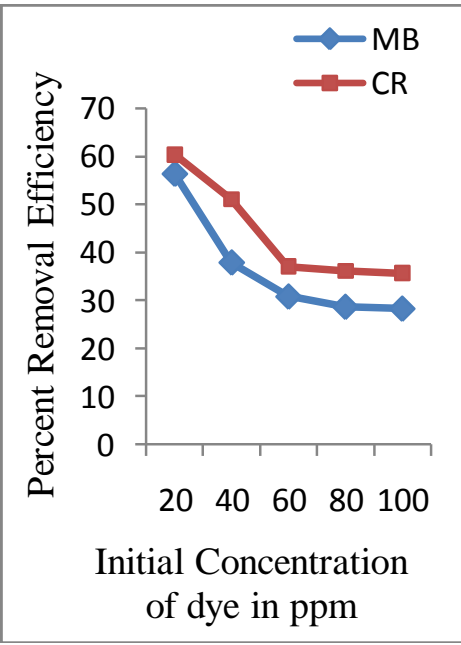

c

Fig.1:- Effect of initial concentration of dyes on percentage removal efficiency of adsorbent at neutral $\mathrm{pH}, 0.5 \mathrm{~g}$ adsorbent dose \& 1 hour contact time for a) PPAC300 b) PPAC400 c) PPAC500 


\section{Effect of adsorbent dose:-}

The percentage removal efficiency of all PPACs was studied with respect to adsorbent dose of 0.2, 0.4, 0.6, 0.8 and $1 \mathrm{~g} / 100 \mathrm{ml}$ of $40 \mathrm{ppm}$ initial dye concentration solution at neutral $\mathrm{pH}$ and one hour contact time. This effect gives an idea of the effectiveness of an adsorbent and ability of the dye to be adsorbed with minimum doses. The results obtained are as shown in figure: 2, from figure it is observed that percentage removal efficiency of dyes increases with increase in adsorbent dose up to $0.8 \mathrm{~g}$ above which no significant change was observed on increasing the dose to $1 \mathrm{~g}$. This is due to the fact that with increasing adsorbent dose weight, the number of adsorption sites available for the adsorbing solute interaction increases (Hameed et al., 2013) as adsorbent surface increases. The percentage removal efficiency is more for Congo red dye than that of the Methylene blue dye for all PPACs. The percentage removal efficiency of PPAC300 is maximum in comparison with others. For $40 \mathrm{ppm}$ initial dye concentration PPAC300 adsorbent found to remove $87.18 \%$ Congo red and $80.36 \%$ Methylene blue dye for $1 \mathrm{~g}$ of adsorbent dose.

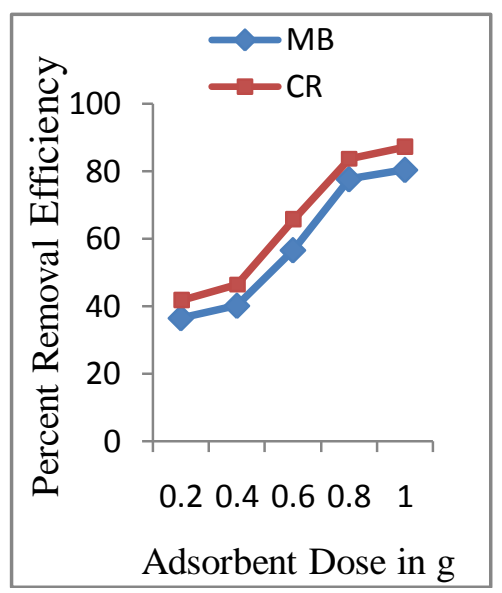

a

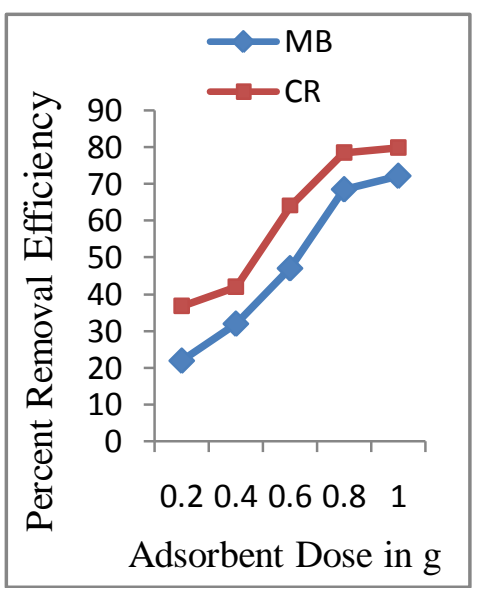

b

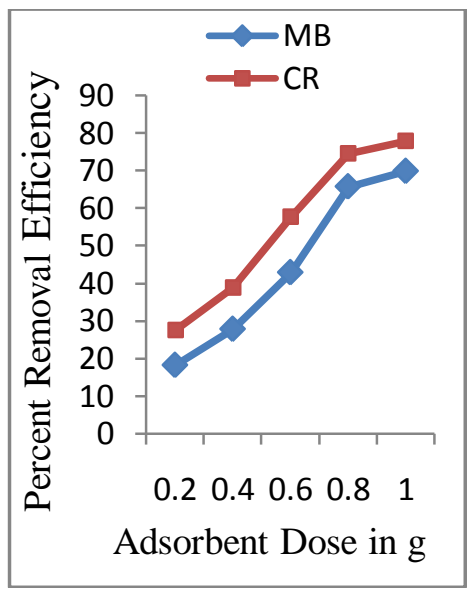

c

Fig 2:- Effect of adsorbent dose on percentage removal efficiency of adsorbent at neutral $\mathrm{pH}, 40 \mathrm{ppm}$ initial dye concentration \& 1 hour contact time for a) PPAC300 b) PPAC400 c) PPAC500

\section{Effect of contact time:-}

The effect of contact time was studied at room temperature at time interval 30, 60, 90, 120 and 150 minutes using $0.5 \mathrm{~g} / 100 \mathrm{ml}$ of adsorbent dose and $40 \mathrm{ppm}$ initial concentration of dyes. The results obtained are shown in figure 3 . From the graph it is noticed that the percentage removal efficiency of all activated carbons increases with increase of contact time up to 90 minutes. After which it appears that there would be no noticeable change in the toxic dyes removal efficiency for further increase in contact time (Banerjee et al., 2015). The percentage removal efficiency is more for Congo red dye than that of the Methylene blue dye for all PPACs. It reveals that the equilibrium adsorption percentage increases with increase in the contact time and approaches to the equilibrium after about 90 minutes. No or slight change in percentage removal efficiency after 90 minutes may due to the repulsive forces between adsorbed dyes on the surface of adsorbent and that in the contacted aqueous sample solution or the equilibrium was reached 


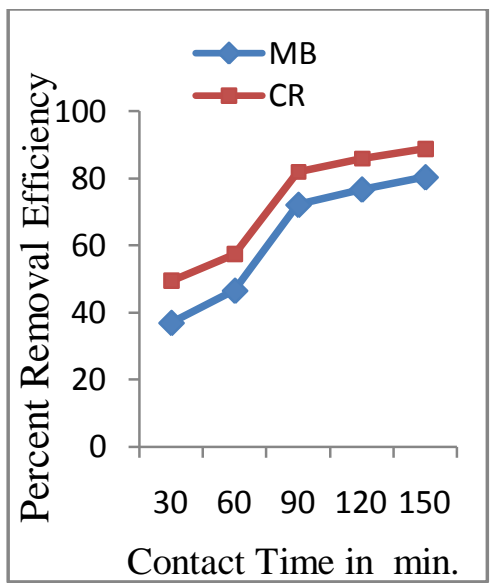

a

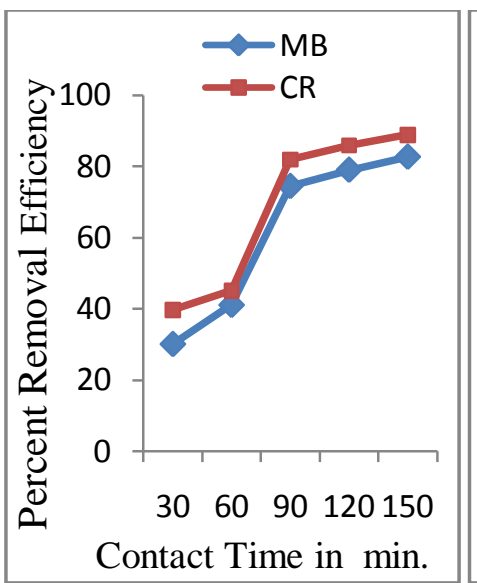

b

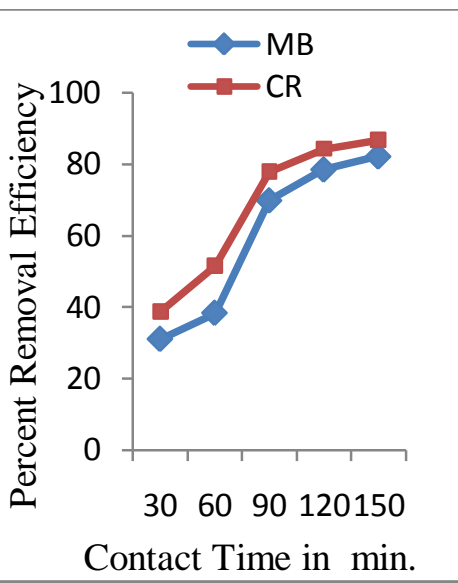

c

Fig 3:- Effect of contact time on percentage removal efficiency of adsorbent at neutral $\mathrm{pH}, 40 \mathrm{ppm}$ initial dye concentration \& $0.5 \mathrm{~g}$ adsorbent dose for a) PPAC300 b) PPAC400 c) PPAC500

\section{Conclusions:-}

The study was carried out to evaluate the toxic dye removal efficiency from the aqueous sample solution using pineapple peel activated carbons (PPAC) as adsorbents at the different initial concentration of dyes, adsorbent dose and contact time. The percentage removal efficiency of activated carbons were increases with increasing dose of adsorbents and the observed trend of the percentage removal efficiency is more for Congo red than that of the Methylene blue dye for all PPACs. The percentage removal efficiency of activated carbons is maximum at the lowest concentration of dyes and decreases with the increase in the initial dye concentration. The effect of contact time reveled that percentage removal efficiency of activated carbons is maximum at 90 minutes and then almost same. Thus PPACs derived from low cost agricultural waste could be fruitfully employed as eco-friendly substituent adsorbent against high cost commercial adsorbents for removal of toxic dyes from industrial waste water to protect environment and life on earth.

\section{Acknowledgements:-}

The authors gratefully acknowledge the Director, Institute of Science, Nagpur and Head, Department of Chemistry, Institute of Science, Nagpur for providing the facilities and support.

\section{References:-}

1. Ashtaputrey S D, Ashtaputrey P D.,(2016): Preparation, characterisation and application of pineapple peel activated carbon as an adsorbent for water hardness removal., Journal of Chemical and Pharamaceutical Research., 8:1030-1034.

2. Azar S., Liew G., Suhardy D., Hafiz F., Hatim I.,(2005): Dye removal from aqueous solution by using adsorption on treated sugarcane Bagasse, American Journal of Applied Sciences., 2 (11):1499-1503.

3. Banerjee S., Sharma G. C., Dubey S., and Sharma Y. C., (2015): Adsorption characteristics of low cost activated carbon for the removal of Victoria blue from aqueous solution, Journal of Mater and Environment Science., 6(8): 2045-2052.

4. Bansal O.P. ,(1996): Heavy metal pollution of soils and plants to sewage irrigation. Journal of Environmental Health.,40: 51-57.

5. Gurses A. Karaca S.,Dogar C.Acikyildiz R.M.,and Yalcim M.,(2004):Determination adsorptive properties of Clay/Water system:Methylene blue sorption., Journal of Coll.Interf.Science.,269:310-314.

6. Hameed K.S., Muthirulan P.,.Minakshi S.M,(2013): Adsorption of Chromotrope dye onto activated carbons obtained from the seeds of various plants:Equilibrium and kinetics studies,Arabian Journal of chemistry.,10:1016

7. Ishaq M., Saeed K., Shoukat A.,.Ahmad I and Rehman A.,(2014): Adsorption of Alizarin dye from aqueous solution on an activated charcoal, International Journal of Science Inventions Today.,3 (6):2014,705-718

8. Jain R.,Mathur M.,and Sikarwar S.,(2006):Removal of Indigo caramine from industrial effluents using low cost adsorbent.,Journal of Scientific and Industrial Research.,26:258-263. 
9. Jyoti Sharma and Beena Janveja, (2008): A study of Removal of congo red from effluents of textile industry using rise husk carbon activated by steam, Rasayan journal of Chemistry.,1(4):936-942.

10. Low K. S. and Lee C. K., (1990): Removal of cationic dyes using coconut husk as an adsorbent, Pertanika, 13 (2):221-228.

11. Mohammad Abd Muslim AL-Tufaily,(2016): Preparation and utilization of corn cob activated carbon for dye removal from aqueous solution, Journal of Babylon University/Engineering Sciences., 24:700-712,

12. Nadzirah K Z, Zainal S , Noriham A, Normah I, Siti Roha A M , Nadya H.(2013): Physio-chemical properties of Pineapple variety N36 harvested and stored at different maturity stages.,International Food Research Journal.,20(1):225-231.

13. Namasivayam C. and Kavitha D., (2004): Removal of Phenol and chlorophenol from water by coir pith carbon equilibrium and rate studies., Journal of Environmental Science and Engineering.,46(3):217-232.

14. Namasivayam C., Kadirvelu K., (1994): Coir pith an agricultural waste byproduct for the treatment of dying waste water, Bioresource Technology.,8:1994, 79-81.

15. Namasivayam C., Prabha D., Kumutha M., (1998): Removal of direct red and acid brilliant blue by adsorption of banana pith, Bioresource Technology., 64:77-79.

16. Nimkar D. A., Chavan S. K., (2014): Removal of congo red dye from aqueous solution using saw dust as an adsorbent. International Journal of Research and Applications.,4 (4):,47-51.

17. Shobin Wang,Bayjoo Y.,Choneib A and Zhu Z.H.,(2005):Removal of dyes from aqueous solution using fly ash and red mud.,Water Research.,39:129-138

18. Uddin M. T., Islam M. A., Mahmud S. Rukanuzzaman M., (2009): Adsorptive removal of methylene blue by tea waste. Journal of Hazard Mater, 164 (1): 53-60

19. Wong Y. C., Senan M. S. R. and N. A. Atiqah, (2013): Removal of methylene blue and malachite dye using different form of coconut fiber as adsorbent. Journal of Basic and Applied Sciences, 9: 172-177.

20. Yue M.C.,Tsung M.T. and Ming K.W.,(2011): Removal of Crystal Violet and Methylene Blue from aqueous solution using soil nano-clays,IPCBEE.,8:,252-254 